\title{
Effect of Allelic Variation in Triticin on Bread- and Chapati- Making Qualities of Wheat (Triticum aestivum)
}

\author{
Sonia Goel · Meenal Rathore $\cdot$ Sapna Grewal $\cdot$ Neha Jain $\cdot$ Binay K. Singh $\cdot$ \\ Arvind K. Ahlawat $\cdot$ Anju M. Singh $\cdot$ Pradeep K. Singh $\cdot$ Nagendra K. Singh
}

Received: 14 July 2014/ Accepted: 22 January 2015/Published online: 28 February 2015

(C) The Author(s) 2015. This article is published with open access at Springerlink.com

\begin{abstract}
Triticin, a legumin-like storage protein of wheat endosperm, was discovered nearly three decades ago but so far there is no report on its effect on the processing quality of wheat that is thought to be determined primarily by prolamins, its major seed storage proteins. To investigate the effect of different classes of seed proteins on wheat quality using a genetic reconstitution approach, we produced 31 near-isogenic lines (NILs) with different alleles of triticin, high molecular weight glutenin subunits (HMW-GS), low molecular weight glutenin subunits (LMW-GS), gliadins and albumins in a common genetic background of wheat variety HD2329 and analysed different quality parameters over a period of 4 years. The NILs did not differ in their flour protein content, but showed significant differences in SDS-sedimentation volume, Farinograph dough stability, bread loaf volume and chapati quality score. Main focus was on triticin for which two NILs with alleles Tri-Ala and Tri-Dla derived from a high-quality Indian wheat variety K68 were analysed. Positive effects of these triticin alleles on dough physical properties, bread loaf volume and chapatti quality score were quite large, comparable to the widely known effect of HMW-GS $5+10$. Specific alleles of HMW-GS, Glu-Ala (subunit 1), Glu-Blb (subunits $7+8$ ), Glu-Bli (subunits $17+18$ ) and Glu-Dld (subunits $5+10$ ) showed strong positive effects, whereas null allele Glu-Alc showed negative effect on the quality of recipient variety HD2329. Similarly, different alleles of LMW-GS showed varying effects with $G l u-A 3 d$, Glu-A3e and Glu-D5a showing positive effects, Glu-A3c showing negative effect and Glu-A3a showing no significant effect. Gliadin alleles generally showed negative effects, whereas albumins showed no significant effect. While results with glutenin and gliadin alleles were as expected, we show here for the first time a significant effect of triticin on the wheat flour quality, suggesting that end-use quality of wheat varieties can be improved by combining specific alleles of triticin.
\end{abstract}

Keywords Bread-making quality $\cdot$ Glutenin subunits $\cdot$ Near-isogenic lines $\cdot$ Triticin $\cdot$ Wheat

S. Goel · S. Grewal · N. Jain · B. K. Singh · N. K. Singh ( $ه)$

National Research Centre on Plant Biotechnology, Indian

Agricultural Research Institute, Pusa Campus, New Delhi

110012, India

e-mail: nksingh@nrcpb.org

M. Rathore · N. K. Singh

Department of Molecular Biology and Genetic Engineering,

G. B. Pant University of Agriculture and Technology, Pantnagar

263145, India

A. K. Ahlawat - A. M. Singh · P. K. Singh

Division of Genetics, Indian Agricultural Research Institute,

Pusa Campus, New Delhi 110012, India

\section{Introduction}

The end-use quality of wheat grain is determined by its protein, starch and lipids constituents of whom gluten proteins play a pivotal role. At the turn of the twentieth century, wheat seed proteins were grouped based on their solubility properties into four classes namely albumin, globulin, gliadin and glutenin [16]. While albumin and globulin are minor proteins of the wheat endosperm and are not known to greatly influence its end-use quality; gliadin and glutenin, the two major components of gluten, are the key determinants of wheat flour quality for making bread, biscuit, noodle and other products [24, 26, 27]. 
Fractionation and reconstitution studies with wheat flour have shown that polymeric glutenin is responsible for the strength or elasticity of wheat flour dough, whereas monomeric gliadin is responsible for its viscosity [14, 15]. Native glutenin fraction is a complex polymer mainly composed of high molecular weight (HMW) and low molecular weight (LMW) subunits whose allelic differences are known to affect the bread-making quality of wheat $[5,11,19]$. The native glutenin fraction also contains small proportion of globulins and albumin but their role in determining wheat end-use quality is not known [15]. Apart from the role of individual glutenin subunits, studies on native proteins without reduction of their disulphide bonds have shown that dough strength and bread-making quality are positively correlated with the proportion and molecular size distribution of polymeric proteins in the total flour protein [5, 9, 33, 34]. Large glutenin polymers are formed by inter-polypeptide disulphide bonds, which give wheat flour dough its unique visco-elastic properties. The HMW subunits of glutenin are encoded by Glu-Al, $G l u-B 1$ and $G l u-D 1$ genes located on the long arm of wheat chromosomes $1 \mathrm{~A}, 1 \mathrm{~B}$, and $1 \mathrm{D}$, respectively $[11,18]$. The $G l u-D 1$ locus is shown to have the single largest effect on bread-making quality, followed by $G l u-B 1$ and $G l u-A l$ loci [11]. The LMW subunits of glutenin are coded by $G l u-A 3$, Glu-B3 and Glu-D3 genes located on the short arm of chromosomes $1 \mathrm{~A}, 1 \mathrm{~B}$ and $1 \mathrm{D}$, respectively, tightly linked to the Gli-1 loci coding for gliadins [31]. The LMW subunits have been quite difficult to study by electrophoresis due to their overlapping size with gliadin polypeptides but after development of a simplified SDS-PAGE procedure, it was shown that allelic differences at $G l u-A 3, G l u-B 3$ and Glu-D3 loci coding for LMW glutenin subunits are equally important in determining the dough properties and breadmaking quality $[5,8,13,35]$.

Gliadins are monomeric proteins and when fractionated by acidic starch or polyacrylamide gel electrophoresis (APAGE), they separate into four groups, namely $\alpha, \beta, \gamma$ and $\omega$ gliadins [40]. Gliadin synthesis is controlled by several related genes of a limited number of multi-gene families located on the short arm of group 1 and 6 chromosomes [41]. Combined studies of HMW glutenin subunits and gliadin composition in different wheat cultivars and progenies have revealed their relative contribution to dough properties [14, 15]. It has been suggested that the effect of gliadins on dough quality should be attributed to their tight genetic linkage with LMW glutenin subunits genes [17]. Purified gliadin is known for its negative effect on dough strength and bread-making properties, and therefore, positive effect of specific $G l i-1 / G l u-3$ complex on dough resistance and extensibility is most likely due to the genetically linked $G l u-3$ alleles due to their polymerization properties [5, 8, 14, 15].
Triticin is a minor seed storage globulin of the wheat endosperm first identified by Singh and Shepherd [28] and subsequently characterized in much detail at the genetic, biochemical, physiological and molecular level. [3, 25, 28, 29, 31, 32, 36]. Triticin genes are located on the short arm of wheat chromosomes $1 \mathrm{~A}$ and $1 \mathrm{D}$, near the centromere far away from the major Gli-1/Glu-3 loci [28, 31]. Triticin is synthesized specifically during the wheat seed development and is deposited in the electron dense inclusion bodies within the main storage protein bodies of the endosperm [3, 29]. Unlike the glutenin and gliadin which are prolamin type proteins (rich in proline and glutamine amino acids), triticin shows homology to the $11-12 \mathrm{~S}$ legumin-like storage globulins of leguminous species [32, 36]. However, the role of triticin in determining wheat dough properties and bread-making quality has not yet been investigated. The aim of this study was to develop a set of near-isogenic lines (NILs) with different alleles of triticin, HMW and LMW glutenin subunits, gliadins and albumins in a common genetic background of Indian bread wheat variety HD2329 and analyse their quality parameters. The variety HD2329 was chosen for its medium bread-making quality so that both positive and negative effects of individual alleles can be observed easily.

\section{Materials and Methods}

\section{Plant Material and Field Experiments}

A set of 31 NILs with different alleles of HMW-GS, LMW-GS, gliadin, triticin and albumin were used (Table 1). NILs were produced by crossing a highly adaptable bread wheat variety HD2329 with donor wheat varieties having different seed storage protein alleles followed by three backcrosses coupled with phenotypic and AFLP marker-based background selection and protein electrophoresis-based foreground selection [22, 23]. Segregating populations for triticin alleles were developed by crossing triticin NILs with the recipient variety HD2329. Two such segregating populations were developed, one each for the Tri-Al and Tri-Dl loci. Homozygous lines for the two triticin alleles were selected from the $F_{2}$ progeny by SDS-PAGE on endosperm half of the seed, while embryo half was grown to obtain $\mathrm{F}_{3}$ seeds for quality analysis. Seeds of all the NILs were multiplied in the experimental fields of IARI, New Delhi, using a completely randomized block design in two replicates with a plot size of 100 plants each sown in a $6 \times 6$ grid design of $3 \mathrm{~m} \times 3 \mathrm{~m}$ during the Rabi seasons of 2007-2010. The field managements were carried out according to standard practices for wheat, and mature grains were harvested for analysis of quality traits. $\mathrm{F}_{3}$ families of triticin segregating lines were grown in a net 
Table 1 Near-isogenic lines (NILs) with different seed storage protein alleles in the background of wheat variety HD2329

\begin{tabular}{|c|c|c|c|c|}
\hline S. no. & NIL no. & Donor locus allele & Donor parent & HD2329 allele \\
\hline 1 & TRI-1 & Tri-Ala & K-68 & $b$ \\
\hline 2 & TRI-2 & Tri-Dla & K-68 & $b$ \\
\hline 3 & HMW-1 & Glu-Ala (1) & UP2121 & $b(2 *)$ \\
\hline 4 & HMW-2 & Glu-A1c (Null) & CS-1BL & $b(2 *)$ \\
\hline 5 & HMW-3 & Glu-B1b $(7+8)$ & CS1A-1B & $b(7+9)$ \\
\hline 6 & HMW-4 & $G l u-B 1 b^{*}\left(7^{*}+8\right)$ & UP1109 & $b(7+9)$ \\
\hline 7 & HMW-5 & Glu-B1i $(17+18)$ & Kalyansona & $b(7+9)$ \\
\hline 8 & HMW-6 & Glu-D1d $(5+10)$ & K-68 & $\mathrm{a}(2+12)$ \\
\hline 9 & LMW-1 & $G l u-A 3 c$ & Kalyansona & $b$ \\
\hline 10 & LMW-2 & Glu-A3e & UP115 & $b$ \\
\hline 11 & LMW-3 & Glu-A3d-1 & UP319 & $b$ \\
\hline 12 & LMW-4 & Glu-A3d-2 & UP1109 & $b$ \\
\hline 13 & LMW-5 & Glu-A3a & CS-1BL & $b$ \\
\hline 14 & LMW-6 & Glu-D5a & CS1A-1B & $b$ \\
\hline 15 & LMW-7 & Glu-B3ks & Kalyansona & $h d$ \\
\hline 16 & GLI-1 & $\omega-G l i-B 1 d$ & Kalyansona & $h d$ \\
\hline 17 & GLI-2 & $\omega-G l i-D 1 b$ & WH147 & $h d$ \\
\hline 18 & GLI-3 & $\omega-G l i-B 1 a$ & CS1A-1B & $h d$ \\
\hline 19 & GLI-4 & $\omega-G l i-B 1 c$ & UP1109 & $h d$ \\
\hline 20 & GLI-5 & $\omega-G l i-A 1 g$ & WH147 & $h d$ \\
\hline 21 & GLI-6 & $\omega-G l i-A 1 h$ & UP115 & $h d$ \\
\hline 22 & GLI-7 & $\omega-G l i-B 1 b$ & UP2121 & $h d$ \\
\hline 23 & GLI-8 & $\gamma-G l i-m a$ & UP1109 & $h d$ \\
\hline 24 & GLI-9 & $\gamma-G l i-m b$ & WH147 & $h d$ \\
\hline 25 & GLI-10 & $\gamma-G l i-m c$ & UP319 & $h d$ \\
\hline 26 & GLI-11 & $\gamma-$ Gli-md & UP115 & $h d$ \\
\hline 27 & GLI-12 & $\gamma$-Gli-me & Sunkota B & $h d$ \\
\hline 28 & ALB-1 & $A l b-m b$ & UP301 & $h d$ \\
\hline 29 & ALB-2 & $A l b-m c$ & UP115 & $h d$ \\
\hline 30 & ALB-3 & $A l b-m f$ & UP1109 & $h d$ \\
\hline 31 & ALB-4 & $A l b-m g$ & K-68 & $h d$ \\
\hline
\end{tabular}

house to obtain enough F4 seeds for the quality analysis using SDS sedimentation and extensigraph tests.

\section{Protein Extraction and SDS-PAGE}

Sequential extraction of seed albumin, gliadin and glutenin were done from crushed endosperm half of single seed ( $\sim 15 \mathrm{mg}$ ) or $20 \mathrm{mg}$ of four samples in $1.5 \mathrm{ml}$ Eppendorf tubes. First, albumin was extracted in $200 \mu \mathrm{l}$ of RO water (18 Ohm) at $25{ }^{\circ} \mathrm{C}$ for $30 \mathrm{~min}$, centrifuged at $15000 \times g$ for $10 \mathrm{~min}$, and then $100 \mu \mathrm{l}$ of the supernatant was mixed with equal volume of $2 \times$ sample buffer [ $2 \%$ SDS, $20 \%(\mathrm{w} / \mathrm{v})$ glycerol, $82.5 \mathrm{mM}$ tris-base, $0.2 \%$ bromophenol blue, $\mathrm{pH}$ 8.0] containing $1 \%(\mathrm{v} / \mathrm{v})$ dithiothreitol. The residue was washed with $0.5 \mathrm{ml}$ of RO water and then extracted with $200 \mathrm{ul}$ of $50 \%(\mathrm{v} / \mathrm{v})$ propan-2-ol, centrifuged at
$15,000 \times g$ for $10 \mathrm{~min}$ as reported earlier [22, 23]. Except for albumins which were extracted at room temperature, all other seed storage proteins were extracted by incubation at $60{ }^{\circ} \mathrm{C}$ for $10-15$ min just before loading in the gel. Glutenin (HMW-GS and LMW-GS) extraction and separation were done according to Singh et al. [35]. Albumins $(30 \mu \mathrm{l})$, glutenins $(25 \mu \mathrm{l})$ and gliadins $(20 \mu \mathrm{l})$ extracts were separated in a $10 \%$ polyacrylamide gels with $1.5 \%$ crosslinking. Electrophoresis was performed in $1.5 \mathrm{~mm}$ thick slab gels of $20 \times 20 \mathrm{~cm}$ dimension using Hoefer SE600 electrophoresis system at a constant current of $40 \mathrm{~mA} / \mathrm{gel}$ for $2.5 \mathrm{~h}$. Triticin was extracted from single seeds in $1 \mathrm{M}$ $\mathrm{NaCl}$ and precipitated with acetic acid as described in Singh et al. [30]. The triticin gels were run for a longer period of $3.5 \mathrm{~h}$ for better resolution of high molecular weight triplet protein bands. After electrophoresis, gels 
were stained in coomassie brilliant blue solution [6 \% (w/ v) trichloroacetic acid, $18 \%$ methanol, $6 \%$ glacial acetic acid and $0.025 \%$ coomassie brilliant blue R250] overnight and destained in $3 \% \mathrm{NaCl}$ solution as described by Sreeramulu and Singh [38].

\section{Measurement of Quality Traits}

\section{Grain Protein Content and Kernel Characteristics}

Grain protein content (GPC) was measured by near infrared reflectance spectrometry (NIRS) from grain samples according to the AACC method [1]. White flour protein content and moisture level were also measured by NIRS and used together with grain hardness index for calculating the amount of water required for Farinograph test [Brabender 1965]. Grain hardness (GH), moisture content (MC), grain diameter (GD) and thousand kernel weight (TKW) were measured on 300 kernels for each sample using Perten Single Kernel Characterization System (SKCS) 4100 system, following manufacturer's protocol (Perten Instruments North America Inc., Springfield, IL).

\section{SDS-Sedimentation Volume Test}

Flour samples were evaluated for bread-making quality using SDS-sedimentation volume (SDS-SV) test [2]. In this method, the volume of material which sediments after mixing flour with a solution of SDS and lactic acid is measured. Milling of grains was performed in a Brabender Junior mill to obtain flour extraction rate of $60 \%$.

\section{Farinograph Test}

Farinograph curves (C.W. Brabender Instruments, Inc., South Hackensack, NJ, USA) were generated according to the AACC method [1]. The $50 \mathrm{~g}$ mixing bowl was used in conjunction with the standard operating speed of $63 \mathrm{rpm}$. The curves were read manually, and different parameters were recorded, including Farinograph water absorption (FAB, $14.0 \%$ moisture basis), the amount of water required to centre the curve on the $500 \mathrm{BU}$ line; dough stability (STA), the difference in time from when the top of the curve first reaches the $500 \mathrm{BU}$ line (arrival time, AT) to when it first leaves the 500 BU line (departure time, DT); mixing tolerance index (MTI), the drop in the curve $5 \mathrm{~min}$ after peak development, measured in BU units; dough development time (DDT), the time required to reach peak dough development; and time to breakdown (TTB), the time from the start of mixing to the time at which the consistency decreases $30 \mathrm{BU}$ from the peak.

\section{Dough Resistance and Extensibility}

The segregating lines of triticin were analysed using texture analyser for extensigraph properties. This was done by TA.XTplus Texture Analyser from Stable Micro Systems using Kieffer extensibility rig. It uses the same principle as Brabender Extensograph, except that the sample is stretched upwards and the dough requirement is low. It provides information about dough resistance to stretching and extensibility by measuring the force to pull a hook through a cylindrically shaped piece of dough [43].

\section{Bread Loaf Volume}

Baking performance was evaluated by doing an optimized straight-dough bake test (Approved Method 10-10B, AACC 1995) using $100 \mathrm{~g}$ of flour (14\% moisture basis). Optimum bake water absorption (\%WA) and mixing time (min) were those resulting in dough with optimal handling characteristics as judged by bakers. Loaf volume $\left(\mathrm{cm}^{3}\right)$ was determined by rapeseed displacement method on fresh loaves.

\section{Chapati-Making Quality}

Chapatis were prepared from whole-wheat flour according to the method developed by Haridas Rao et al. [10]. Flour (200 g, $14.0 \%$ moisture basis) and water as determined from a 500 B.U. Farinograph trace were mixed in a Hobart dough kneader (HL $120 \mathrm{~Hz}$ 50/60) for $5 \mathrm{~min}$. The dough was rested for $10 \mathrm{~min}$ before being cut into four equal sections of $40 \mathrm{~g}$ each. A section of the dough was then placed on a rolling board with a thickness guide of $1.5 \mathrm{~mm}$. The dough was rolled in one direction, inverted, rotated at $90^{\circ}$ and rerolled. The sheeted dough was cut with a circular die to get a 12-cm diameter uniform chapati (Fig. 1a). The raw chapati was placed on a preheated griddle at $215^{\circ} \mathrm{C}$. The chapati was cooked for $70 \mathrm{~s}$ on one side, flipped, and then cooked for $85 \mathrm{~s}$ on the second side. The cooked chapati was quickly transferred $(<10 \mathrm{~s})$ to an adjacent heater and allowed to puff for $20 \mathrm{~s}$ before removal and cooling at room temperature for $10 \mathrm{~min}$.

Puffing height was recorded by a scale with sliding bar (Fig. 1b). Puffing height of chapati between 0 and $5 \mathrm{~cm}$ chapati was given 5 points. Chapati was also evaluated by a trained panel of four judges and scored (0-10) subjectively for the following quality parameters; appearance, tearing strength, pliability, aroma and eating quality (0-15). After taking one set of observations, chapati was placed in a resealable plastic bag and stored for $4 \mathrm{~h}$ before next round of evaluation. Again after $4 \mathrm{~h}$ chapattis were evaluated for tearing strength and pliability (score 0-10). The higher the score, the better the quality of chapatti. Assessments were 

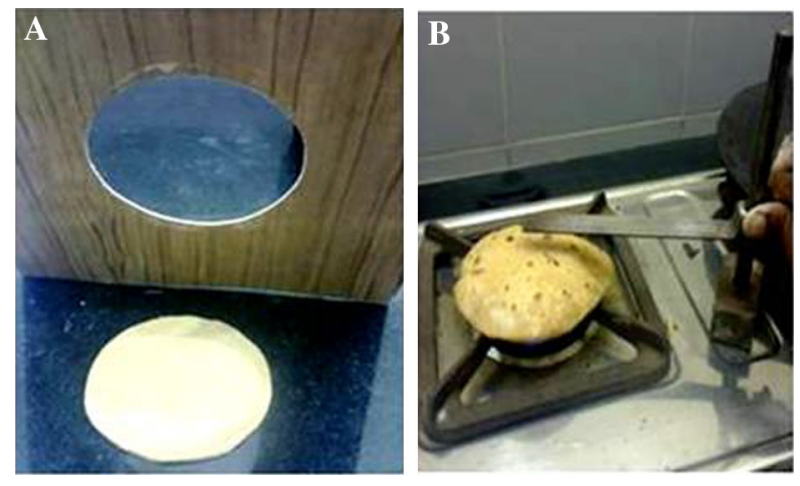

Fig. 1 Simple equipment used for chapati making and puffing. a cutting of uniform size chapati using a plastic manifold with round hole, $\mathbf{b}$ measurement of chapati puffing height

made in duplicate, and scores of all the panellists were averaged.

\section{Statistical Analysis}

Analysis of variance (ANOVA) was done using SPSS software package ver. 16. The seed samples of all 4 years were taken for the analysis of SDS sedimentation and protein content, while only two-year seeds were used for Farinograph and baking quality tests. $T$ test was performed for assessing the significance of differences among the means for the NILs and triticin segregating lines at $0.5 \%$ $P$ level of significance.

\section{Results}

\section{Characterization of Seed Protein NILs}

Total thirty-one NILs were developed with different seed storage protein alleles in the common genetic background of bread wheat variety HD2329. Different seed protein genes, the allele for which individual NIL differed from the recipient variety HD2329, donor variety and corresponding allele in the recipient variety are shown in Table 1 . Genes and alleles for which no recognized symbols are available, e.g. albumin polypeptides, were assigned new temporary symbols [23]. Field observations over 4 years showed that the NILs were quite similar in appearance and yield performance to the recipient variety HD2329, except for white glume colour in some of the NILs for Gli-Bl/Glu-B3 loci, namely [GLI-1,3,4,7 and LMW-7], and the rest of NILs were brown in glume colour like recipient variety HD2329. This was due to a tight genetic linkage between gene for red glume colour and Gli-B1/Glu-B3 locus on the short arm of chromosome 1B [12].
The NILs were characterized for their complete seed protein profile by SDS-PAGE to check for similarity of non-target protein loci with the recipient parent HD2329. There were two NILs with different alleles of triticin, namely TRI-1 and TRI-2, corresponding to triticin alleles Tri-Ala and Tri-Dla, respectively (Fig. 2). The recipient variety HD2329 had Tri-Alb and Tri-DIb alleles at these loci resulting in a narrow triplet band compared to NIL TRI-1 which had a faster moving Tri-A1 band and NIL-2 which had a slower moving Tri-D1 band resulting in wider triplet bands in the two NILs. The intensity of triticin bands was also consistently darker in the two NILs as compared to HD2329. Both the triticin NILs showed identical electrophoretic profiles for HMW-GS, LMW-GS, gliadin and albumin fractions.

There were six HMW-GS NILs, two for Glu-Al locus (Glu-Ala and Glu-Alc with subunit 1 and null, respectively), three for Glu-B1 locus $\left(G l u-B 1 b, G l u-B 1 b^{*}\right.$ and Glu-Bli with subunit $7+8,7^{*}+8$ and $17+18$, respectively) and one for the Glu-Dl locus (Glu-Dld with subunit $5+10$ ). SDS-PAGE analysis established that the

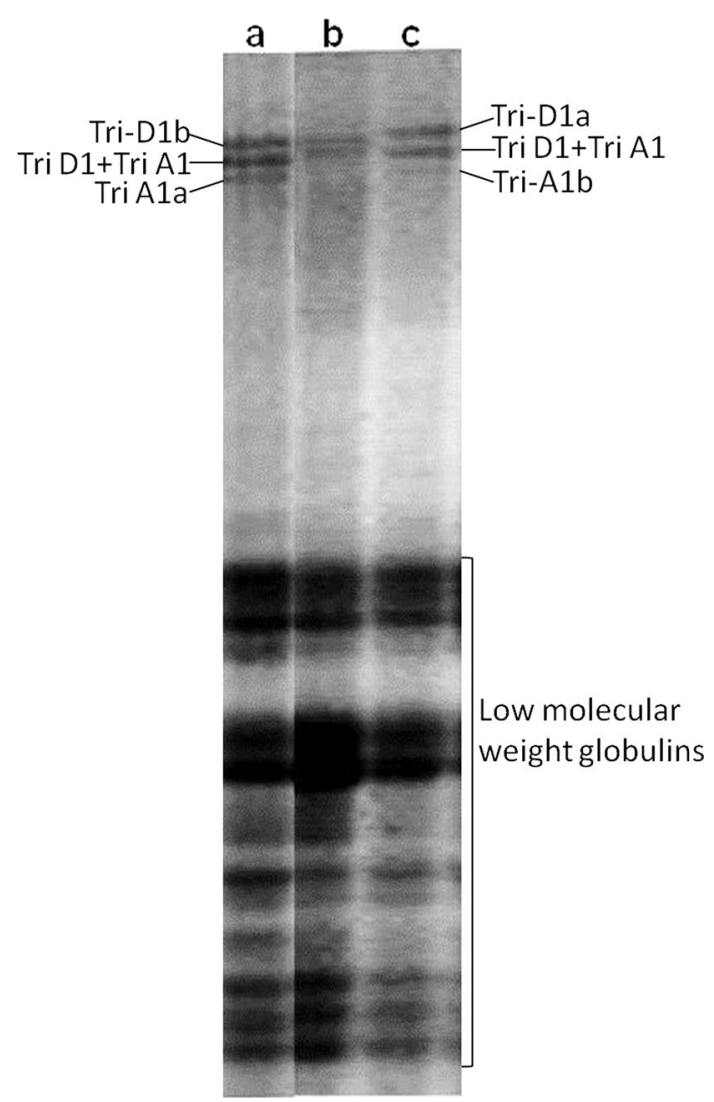

Fig. 2 SDS-PAGE patterns of NILs for triticin seed storage globulins. $a$ NIL Tri-A1a, $b$ Recipient parent HD2329, $c$ NIL TriD1a. Slowest moving dark band in the triplet is pure Tri-D1, fastest moving faint band is pure Tri-A1, whereas middle dark band is a heteromer of Tri-D1 and Tri-A1 subunits 
HMW-GS NILs differed for the targeted HMW subunit only, and their profiles for other HMW subunits, LMW subunits, gliadin, albumin and triticin proteins were identical to the recurrent parent HD2329 (Fig. 3). There were seven NILs for LMW glutenin subunits of which five were for GluA3 locus (Glu-A3a, Glu-A3c, two NILs with Glu$A 3 d$ from separate donors and $G l u-A 3 e$ ), one each for GluD5 (Glu-D5a) and an uncharacterized locus "Glu-B3ks" from donor variety Kalyansona (Fig. 4a). The HMW glutenin subunits, albumins and triticin profiles of the LMWGS NILs were identical to the recipient parent HD2329, but there were differences in their gliadin profiles due to tight linkage between genes for LMW glutenin subunits and gliadins (Fig. 4b). Only two of the seven LMW-GS NILs namely LMW-2 and LMW-6 showed gliadin patterns identical to HD2329, and the remaining five LMW-GS NILs showed differences in the $\omega$ - and $\gamma$-gliadin regions as marked in Fig. 4b. Interestingly, NILs LMW-3 and LMW4 both have the same LMW Glu-A3d allele but they differ for gliadin patterns. LMW-3 NIL has different $\omega$-gliadin pattern which can be due to some insufficient backcrossing or rare recombination between Glu-A3 and GliAl loci while LMW-4 NIL gliadin pattern is similar to HD2329. There were 12 NILs with different gliadin alleles; seven of these (Gli-1 to Gli-7) differed in the $\omega$-gliadin region, while remaining five (Gli-8 to Gli-12) differed in the $\gamma$ -

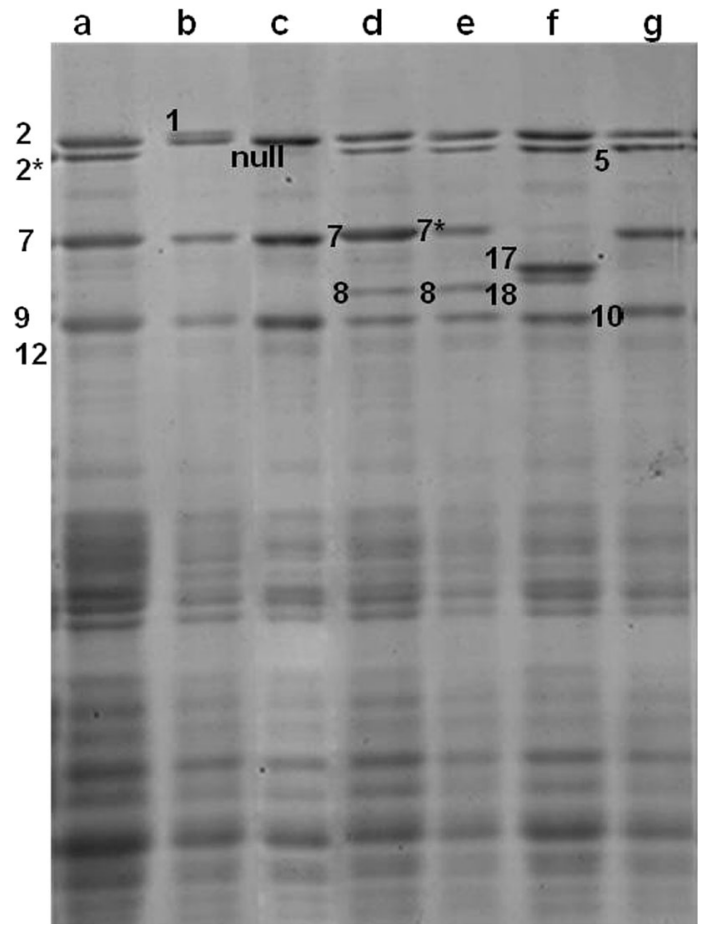

Fig. 3 SDS-PAGE patterns of HMW glutenin subunits (HMW-GS) NILs. $a$ Recipient parent HD2329, $b$ NIL GluA1a, $c$ NIL GluA1c, $d$ NIL Glu-B1b, $e$ NIL Glu-B1b*, $f$ NIL Glu-B1i, $g$ NIL Glu-D1d. Relevant HMW-GS subunits are marked
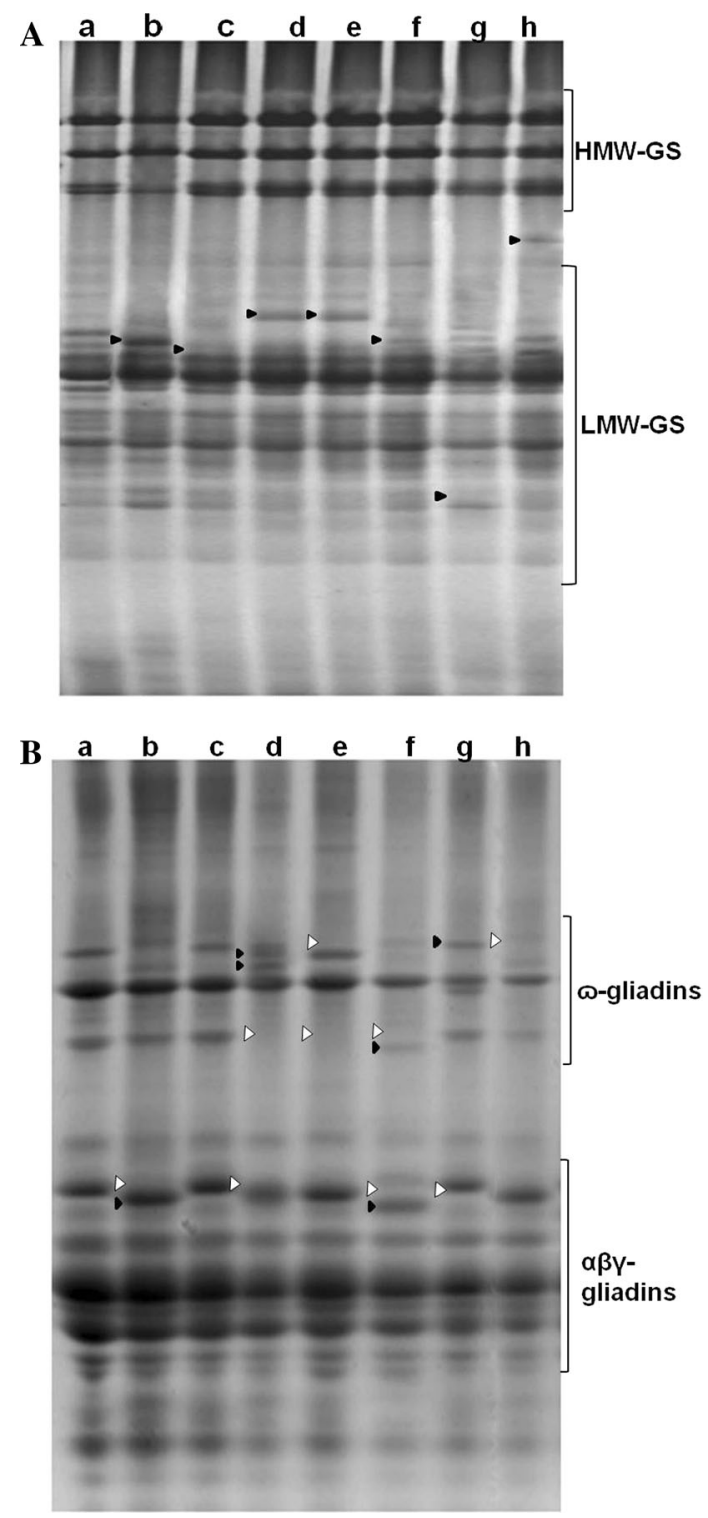

Fig. 4 SDS-PAGE pattern of NILs for LMW glutenin subunits (LMW-GS). a Separation of LMW-GS alleles (marked with right pointing triangle, missing bands marked with open triangles). b Separation of gliadins from the LMW-GS NILs. $a$ Recipient parent HD2329, $b$ NIL Glu-A3c, $c$ NIL Glu-A3e, $d$ NIL Glu-A3d-1, $e$ NIL Glu-A3d-2, $f$ NIL Glu-A3a, $g$ NIL Glu-D5a, $h$ NILGlu-B3ks. Differences in gliadin patterns of LMW-GS NILs are due to tight linkage between the two loci

gliadin region (Fig. 5a). SDS-PAGE analysis showed that similar to the LMW-GS NILs, gliadin NILs showed differences in their LMW-GS profiles due to tight genetic linkage between the two loci (Fig. 5b). The LMW-GS are divided into two groups, $\mathrm{B}$ and $\mathrm{C}$ subunits, based on their size distribution. Variation in the LMW-GS of these NILs was mainly in the slower moving B group of subunits, variation in the $\mathrm{C}$ group of subunits was limited to absence in the $\gamma$-gliadin NILs of one of the three subunits of 
Fig. 5 SDS-PAGE pattern of NILs for Gliadins. a Separation of gliadins alleles (marked with right pointing triangle, missing bands marked with open triangles). b Separation of LMW glutenin subunits from the gliadin NILs. $a$ Recipient parent HD2329, $b$ NIL Gli-B1d, $c$ NIL Gli-D1b, $d$ NIL Gli-B1a, $e$ NIL Gli-B1c, $f$ NIL Gli-A1g, $g$ NIL Gli-A1h, $h$ NIL Gli-B1b, $i$ NIL $\gamma$-gli ma, $j$ NIL $\gamma$-gli mb, $k$ NIL $\gamma$-gli mc, $l$ NIL $\gamma$-gli md, $m$ NIL $\gamma$-gli me. Differences in LMW glutenin subunit patterns of gliadin NILs are due to tight linkage between the two loci
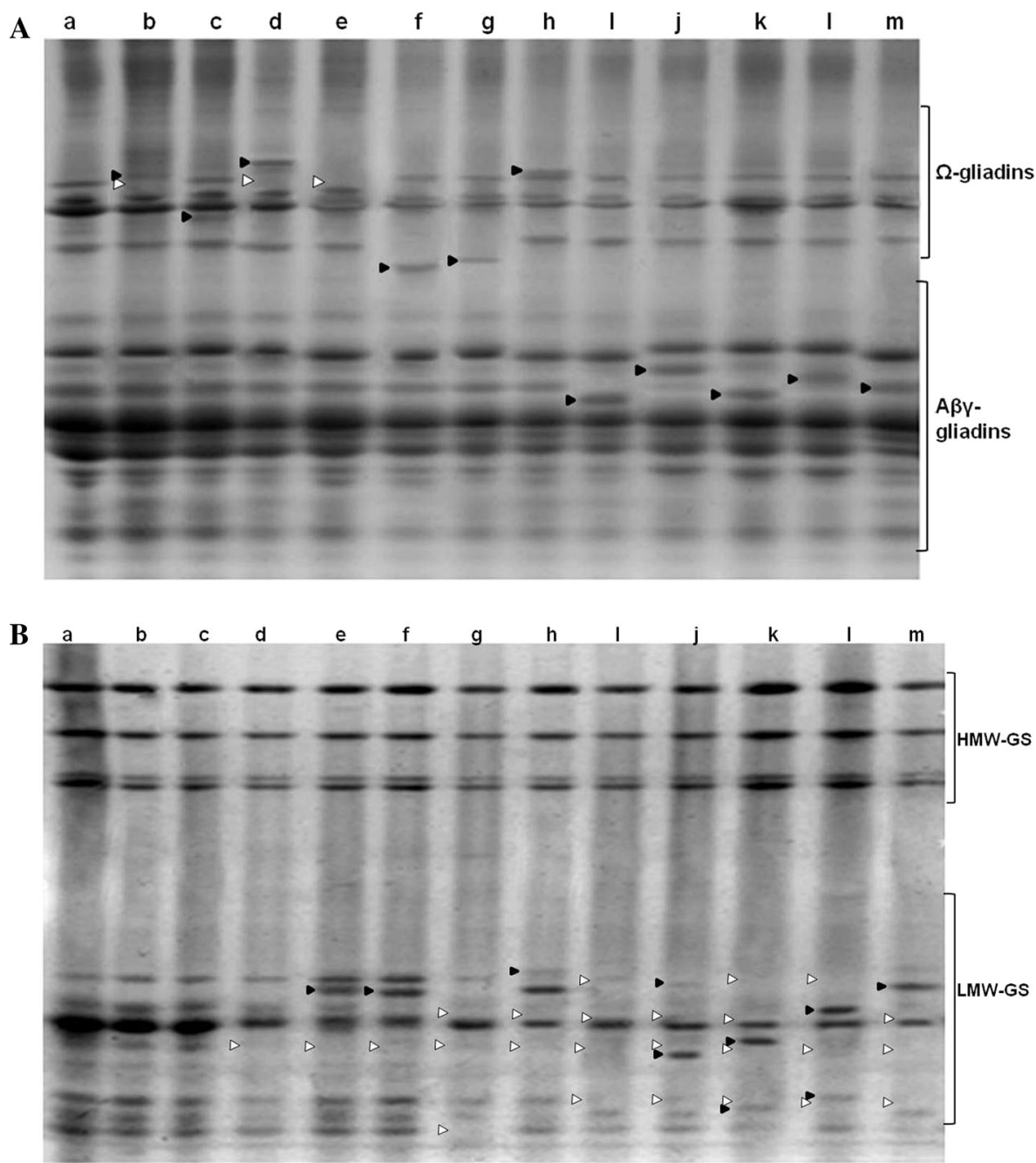

HD2329. HMW-GS, albumin and triticin profiles of the gliadin NILs were identical to the recipient variety HD2329. There were four NILs with different albumin alleles for which temporary new symbols $A l b-m c, A l b-m f$, $A l b-m b$ and $A l b-m g$ were assigned as there were no gene symbols available for these in the literature (Fig. 6).

\section{Effect of Allelic Variation in Seed Proteins on Quality}

The thirty-one NILs were analysed for a range of grain quality parameters considered important for the end-use products namely bread, biscuit and chapati. A single kernel characterization system (SKCS) was used for the analysis of grain hardness, TKW and grain moisture content but these traits did not show significant variation among the NILs, except for TKW which varied significantly between 33.5 and $39.5 \mathrm{~g}$, which is important for flour yield during milling of the wheat grains (Table 2). Further there was no significant difference for grain protein content among the NILs and recipient variety HD2329 (Table 2). This shows that different alleles of seed storage proteins had no relationship with the above quality parameters. However, there were significant differences among NILs for SDS-sedimentation volume, Farinograph dough development time, dough stability and bread loaf volume, showing that these parameters were affected by the seed storage protein allelic composition. Thirty-one NILs analysed in this study represented all four classes of seed proteins. The major storage proteins glutenin and gliadin showed significant positive or negative effect on the dough and bread-making quality of the base wheat variety HD2329, whereas albumin NILs showed no significant effect as also described in the published literature [21]. The most important novel finding of our study was significant positive effect of triticin on wheat quality parameters. Effect of allelic variation in seed protein on different wheat quality parameters are described below.

\section{SDS-Sedimentation Volume}

Sodium dodecyl sulphate-sedimentation volume (SDS-SV) measures degree of sedimentation of wheat flour suspended in a lactic acid-SDS medium during a standard time of 


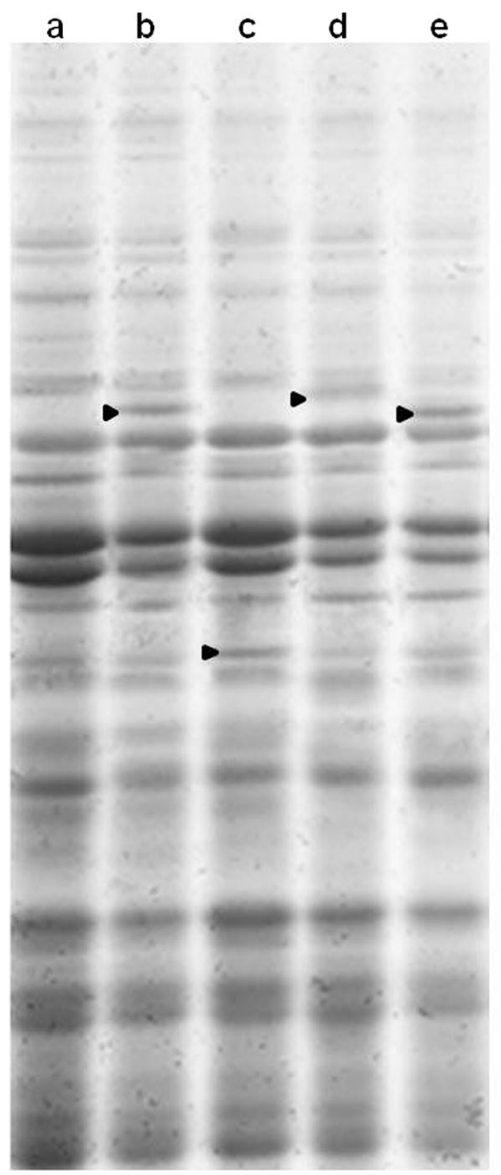

Fig. 6 SDS-PAGE pattern of NILs for seed albumins. Relevant albumin proteins are marked with right pointing triangle. $a$ recipient parent HD2329, $b$ NIL Alb-mc, $c$ NIL Alb-mf, $d$ NIL Alb-mg, $e$ NIL Alb-mh

settling [2]. The SDS-SV value depends on the protein quality and provides an indication of wheat gluten strength. Triticin NILs, with alleles Tri-Ala and Tri-Dla, showed highly significant positive effect on SDS-SV, which was comparable to the effect of HMW glutenin subunits $5+10$ known for their strong positive impact on bread-making quality [17]. Effect of Tri-Dla was comparatively more pronounced than Tri-Ala (Table 2). The HMW-GS NILs with alleles Glu-Ala (subunit 1 ), Glu-Blb (subunit $7+8$ ), Glu-B1b* (subunit $7^{*}+8$ ), Glu-B1i (subunit $17+18$ ) and Glu-Dld (subunit $5+10$ ) showed significant positive effect on SDS-SE of HD2329, while Glu-Alc (Null allele) showed significant negative effect in 4 years of evaluation (Table 2). All the HMW-GS alleles were positively behaving towards SDS-SV, and only Glu-Alc (Null allele) was behaving negatively. There were seven NILs for LMW-GS, five of which represented different alleles of Glu-A3 locus. LMW NILs for allele Glu-A3c were showing significantly negative effect from HD2329 and that of Glu$A 3 a$ was showing no effect, and the rest of the LMW NILs (Glu-A3e, Glu-A3d, Glu-D5a and Glu-B3ks) were showing positive effect over recurrent parent for SDS-SV test. Two separate NILs with Glu-A3d showed strong positive effect over recurrent parent HD2329 but effect of NIL Glu-A3d-1 was lower than Glu-A3d-2 (Table 2). This could be due to difference in the linked gliadin polypeptides as Glu-A3d-1 has multiple $\omega$-gliadin bands which have negative effect of dough strength. All the twelve gliadin NILs showed either negative or no significant effect on the SDS-SV of recipient variety HD2329. The albumin NILs showed no significant effect on SDS-SV.

\section{Farinograph Physical Dough Properties}

Similar to the effect on SDS-SV both the triticin NILs, TriA1a and Tri-D1a, showed highly significant positive effect on dough stability but no effect on farinograph dough development time (Table 2). HMW glutenin subunit NILs with alleles Glu-Ala (1), Glu-Blb $(7+8), G l u-B 1 b^{*}$ $\left(7^{*}+8\right), \quad$ Glu-Bli $(17+18)$ and Glu-Dld $(5+10)$ showed significant positive effects on Farinograph dough stability over HD2329, while Glu-Alc (null allele) showed significant negative effect. LMW-GS NILs Glu-A3c showed significant negative effect on Farinograph dough stability, while Glu-A3a showed no effect rest all the LMW NILs (Glu-A3e, Glu-A3d, Glu-D5a and Glu-B3ks) showed positive effect over recurrent parent for Farinograph dough stability test. Farinograph dough development time showed no significant difference over HD2329 except for allele Glu-D5a which has a low dough development time. All the gliadin NILs, except $\gamma$-Gli-me and $\omega$-Gli-B1b showed significant negative effect, while albumin NILs either showed significantly negative (Alb-mf) or no significant effect (Alb-ma, Alb-mb and -Alb-mg) on dough stability (Table 2). All the gliadin alleles showed no significant effect except $\omega$-Gli-B1c, $\omega$-Gli-A1g and $\gamma$-Gli-md which behaved negatively for dough development time. All the albumins also showed low dough development time.

\section{Bread Loaf Volume}

As expected from the data on SDS-SV and Farinograph physical dough properties, triticin alleles Tri-Ala and TriDla showed highly significant positive impact on the loaf volume of wheat variety HD2329 that was consistent in 2 years of testing. The effect of triticin alleles Tri-Ala and Tri-Dla coming from a traditional high-quality wheat variety K68 was as high as the effect of well-known HMW glutenin subunits $5+10$. The bread loaf volume was $620 \mathrm{cc}$ for Glu-Dld, whereas it was $630 \mathrm{cc}$ and $610 \mathrm{cc}$, for Tri-Dla and Tri-Ala, respectively as compared to $550 \mathrm{cc}$ for HD2329. (Table 2; Fig. 7). HMW-GS (NILs Glu-A1a, Glu-B1b, Glu-B1b*, Glu-B1i and Glu-D1d) showed significant positive effect, while Glu-A1c showed significant 
negative effect on the loaf volume over HD2329 (Table 2). Among the LMW-GS NILs, only Glu-A3d-1, Glu-A3d-2 and Glu-D5a showed significant positive effect on loaf volume, and the remaining LMW-GS NILs (Glu-A3c, GluA3e, Glu-A3a and Glu-B3ks) showed negative or no effect on bread loaf volume over HD2329. All the gliadin NILs showed significant negative effect on loaf volume except $\omega$-Gli-B1d and $\omega$-Gli-B1a which had no significant effect (Table 2). Albumin NILs had no significant effect on bread loaf volume as compared to the recurrent parent HD2329 (Table 2).

\section{Chapati Quality Score}

The bulk of Indian wheat is consumed in the form of chapati, and it is realized that over the years during and post green revolution era, the chapati quality of Indian wheat varieties has declined. Thus, some of the older varieties grown in the central India, so called MP wheat, still fetch premium price in the market [42]. Similar to their effect on SDS-SV, dough physical properties and bread loaf volume, triticin alleles Tri-Ala and Tri-Dla showed significant positive impact on chapati quality score also, which was consistent in 2 years of testing. We evaluated the chapati-making quality of HMW-GS and LMW-GS NILs and found that all the HMW-GS and LMW-GS NILs generally showed positive effects on the chapati quality of HD2329, except for alleles HMW-GS Glu-Alc and LMWGS Glu-A3a, Glu-A3e, Glu-A3c and Glu-D5a which showed no significant effect. None of the gliadin and albumin alleles showed significant effect on chapati quality score.

\section{Validation of the Effect of Triticin Alleles}

in Segregating Bi-Parental Populations

For further validation of the effect of triticin alleles TriAla and Tri-Dla, two segregating populations were developed by crossing the respective triticin NILs with recipient variety HD2329. Homozygous lines with two segregating alleles of the Tri-Al and Tri-Dl genes were selected by SDS PAGE. The triticin patterns of each Tri-Ala, Tri-Alb, Tri-Dla and Tri-Dlb homozygous line are shown in Fig. 8. Tri-Ala and Tri-Dla were obtained from K68, the donor variety of triticin NILs, whereas Tri-Dlb and Tri-Alb were from recurrent parent HD2329. Twenty eight such homozygous $\mathrm{F}_{3}$ segregating lines were multiplied in the net house, and bulk $\mathrm{F}_{4}$ seeds were harvested for quality analysis by SDS-SV and a small-scale dough Extensigraph. Effect of Tri-Dla and Tri-Ala alleles was significantly positive on SDS-SV and dough Extensiograph force over HD2329. The overall effect of all the four triticin alleles was significant on SDS sedimentation value $(P<0.05)$ and
Extensiograph force but extensibility was not affected significantly (Table 3). Tri-Dla and Tri-Dlb alleles gave consistently higher Extensigraph force value than HD2329 but the effect of Tri-Dla was higher than Tri-Dlb. Similarly, the effect of Tri-Ala was higher than Tri-Alb allele (Fig. 8).

\section{Discussion}

A wheat cultivar can produce good quality bread even with moderate protein content, if the protein quality is good. In fact, in many breeding programmes, consciously or not, some HMW-GS alleles, in particular Glu-Dld (subunits $5+10$ ), were frequently used for increasing end-use quality [38]. Earlier studies have provided evidence for strong association between the presence of specific HMWGS alleles and bread-making quality [17, 20]. Further studies have shown that allelic variations in both HMW-GS and LMW-GS are important in determining the breadmaking quality of wheat flour [7]. In our study, no significant difference was found in the protein content of the thirty-one NILs with different seed storage protein alleles, so the effect on wheat quality was primarily due to protein quality i.e. amino acid sequence variation of alleles. A number of studies have been done for evaluating the effects of different HMW, LMW glutenin subunits and gliadin alleles on bread-making quality of wheat but contribution of wheat triticin has not yet been investigated. Triticin is a minor seed storage protein which accounts for only about $5 \%$ of the total endosperm protein in wheat. It is leguminlike protein and has a lysine-rich repetitive domain in its hyper variable region which offers new opportunities to genetic engineers for increasing lysine content of wheat [36]. Our study found two alleles of triticin showing significant positive effect on bread-making quality parameters. SDS sedimentation volumes were 46 and $44 \mathrm{ml}$ in Tri-Dla and Tri-Ala, respectively, which are comparable to the effect of HMW-GS Glu-Dld with volume of $45 \mathrm{ml}$. Glu-Dld has already proved to be a good contributor towards bread-making quality. Triticin allele's effect was comparable to Glu-Dld consistently in the 4 years trials. The effect was more pronounced on dough strength where Tri-Dla and Tri-Ala NILs showed Farinograph dough stability time of 17.5 and $16 \mathrm{~min}$, respectively, compared to $16 \mathrm{~min}$ for Glu-Dld NIL and $11 \mathrm{~min}$ for the recipient parent HD2329. Similar positive effect was seen on bread loaf volume which was over $610 \mathrm{cc}$ for the triticin NILs as compared to $550 \mathrm{cc}$ for HD2329.

Alleles of HMW-GS and LMW-GS showed expected effects as described in the earlier studies. All the HMW-GS alleles, except the null allele Glu-Alc showed positive effect on SDS-SV and Farinograph dough stability. Earlier 
Table 2 Grain and flour quality scores of thirty-one near-isogenic lines with different seed storage protein alleles in wheat variety HD2329

\begin{tabular}{|c|c|c|c|c|c|c|c|c|c|}
\hline \multirow{2}{*}{$\begin{array}{l}\text { Protein } \\
\text { class }\end{array}$} & \multirow{2}{*}{ NIL allele } & \multirow{2}{*}{$\begin{array}{c}\text { Thousand } \\
\text { kernel } \\
\text { weight } \\
(\mathrm{g})^{*}\end{array}$} & \multirow{2}{*}{$\begin{array}{l}\text { Grain } \\
\text { protein } \\
\text { content } \\
(\%)^{*}\end{array}$} & \multirow{2}{*}{$\begin{array}{c}\text { Grain } \\
\text { hardness } \\
\text { index* }\end{array}$} & \multirow{2}{*}{$\begin{array}{c}\text { SDS-SV } \\
(\mathrm{ml})^{*}\end{array}$} & \multicolumn{2}{|c|}{ Farinograph } & \multirow{2}{*}{$\begin{array}{c}\text { Bread } \\
\text { loaf } \\
\text { volume } \\
(\mathrm{cc})^{* *}\end{array}$} & \multirow{2}{*}{$\begin{array}{l}\text { Chapati } \\
\text { quality } \\
\text { score** }\end{array}$} \\
\hline & & & & & & $\begin{array}{c}\text { DDT } \\
(\min )^{* *}\end{array}$ & $\begin{array}{l}\text { Stability } \\
(\mathrm{min}) * *\end{array}$ & & \\
\hline & HD2329 & $36.5^{b}$ & 12.8 & 92.2 & $35.3^{\mathrm{c}}$ & $4.8^{\mathrm{a}}$ & $10.5^{\mathrm{c}}$ & $550^{\mathrm{c}}$ & $60^{c}$ \\
\hline \multirow[t]{2}{*}{ Triticin } & Tri-D1a & $36.8^{b}$ & 12.6 & 91.3 & $46.0^{\mathrm{a}}$ & $4.5^{\mathrm{a}}$ & $17.3^{\mathrm{a}}$ & $630^{a}$ & $79^{\mathrm{a}}$ \\
\hline & Tri-Ala & $35.8^{\mathrm{b}}$ & 12.6 & 90.9 & $44.0^{\mathrm{a}}$ & $4.8^{\mathrm{a}}$ & $15.5^{\mathrm{a}}$ & $610^{\mathrm{a}}$ & $79^{a}$ \\
\hline \multirow{6}{*}{$\begin{array}{l}\text { HMW- } \\
\text { glutenin } \\
\text { subunits }\end{array}$} & Glu-A1a & $36.2^{b}$ & 13.3 & 93.4 & $38.8^{b}$ & $4.3^{\mathrm{a}}$ & $13.4^{b}$ & $610^{a}$ & $80^{a}$ \\
\hline & Glu-A1c & $36.7^{\mathrm{b}}$ & 13.4 & 90.1 & $32.8^{\mathrm{d}}$ & $4.6^{\mathrm{a}}$ & $8.0^{\mathrm{d}}$ & $520^{d}$ & $65^{c}$ \\
\hline & Glu-B1b & $39.5^{\mathrm{a}}$ & 13.0 & 93.3 & $40.0^{b}$ & $5.2^{\mathrm{a}}$ & $13.3^{b}$ & $570^{\mathrm{b}}$ & $79^{a}$ \\
\hline & Glu-B1b* & $34.6^{b}$ & 13.3 & 92.7 & $39.0^{\mathrm{b}}$ & $5.3^{\mathrm{a}}$ & $13.3^{b}$ & $580^{b}$ & $79^{a}$ \\
\hline & Glu-B1i & $39.4^{\mathrm{a}}$ & 12.8 & 91.2 & $39.5^{b}$ & $4.5^{\mathrm{a}}$ & $14.8^{b}$ & $600^{\mathrm{a}}$ & $79^{a}$ \\
\hline & Glu-D1d & $39.5^{\mathrm{a}}$ & 12.9 & 96.4 & $45.0^{\mathrm{a}}$ & $4.5^{\mathrm{a}}$ & $16.3^{\mathrm{a}}$ & $620^{\mathrm{a}}$ & $79^{a}$ \\
\hline \multirow{7}{*}{$\begin{array}{l}\text { LMW- } \\
\text { glutenin } \\
\text { subunits }\end{array}$} & Glu-A3c & $37.7^{\mathrm{a}}$ & 12.6 & 93.7 & $32.0^{\mathrm{d}}$ & $4.3^{\mathrm{a}}$ & $7.8^{d}$ & $460^{\mathrm{e}}$ & $60^{c}$ \\
\hline & Glu-A3e & $36.4^{b}$ & 13.3 & 89.8 & $38.8^{b}$ & $4.3^{\mathrm{a}}$ & $12.5^{b}$ & $540^{\mathrm{c}}$ & $60^{c}$ \\
\hline & Glu-A3d-1 & $34.6^{b}$ & 13.2 & 89.5 & $37.0^{b}$ & $4.7^{\mathrm{a}}$ & $14.8^{b}$ & $570^{b}$ & $70^{b}$ \\
\hline & Glu-A3d-2 & $37.5^{\mathrm{a}}$ & 13.5 & 93.9 & $46.0^{a}$ & $5.8^{\mathrm{a}}$ & $12.8^{b}$ & $600^{a}$ & $70^{b}$ \\
\hline & Glu-A3a & $35.7^{b}$ & 13.4 & 94.1 & $35.5^{c}$ & $4.4^{\mathrm{a}}$ & $10.4^{\mathrm{c}}$ & $540^{c}$ & $65^{c}$ \\
\hline & Glu-D5a & $33.7^{b}$ & 13.5 & 89.3 & $39.0^{b}$ & $3.8^{\mathrm{b}}$ & $12.1^{b}$ & $580^{b}$ & $65^{c}$ \\
\hline & Glu-B3ks & $33.8^{b}$ & 13.0 & 91.1 & $37.0^{b}$ & $5.5^{\mathrm{a}}$ & $12.2^{b}$ & $500^{d}$ & $69^{b}$ \\
\hline \multirow[t]{12}{*}{ Gliadin } & $\omega$-Gli-B1d & $37.2^{\mathrm{a}}$ & 12.8 & 94.8 & $35.0^{\mathrm{c}}$ & $5.5^{\mathrm{a}}$ & $7.8^{d}$ & $540^{\mathrm{c}}$ & $59^{c}$ \\
\hline & $\omega$-Gli-D1b & $38.4^{\mathrm{a}}$ & 12.8 & 90.7 & $33.0^{d}$ & $5.3^{\mathrm{a}}$ & $7.8^{d}$ & $510^{d}$ & $59^{c}$ \\
\hline & $\omega$-Gli-B1a & $37.9^{a}$ & 12.6 & 92.7 & $31.0^{d}$ & $4.3^{\mathrm{a}}$ & $7.1^{\mathrm{d}}$ & $555^{c}$ & $59^{c}$ \\
\hline & $\omega$-Gli-B1c* & $37.1^{\mathrm{a}}$ & 12.5 & 88.6 & $30.3^{d}$ & $3.8^{b}$ & $4.6^{\mathrm{e}}$ & $450^{\mathrm{e}}$ & $59^{\mathrm{c}}$ \\
\hline & $\omega$-Gli-A1g & $37.9^{\mathrm{a}}$ & 13.1 & 93.9 & $31.3^{d}$ & $3.5^{b}$ & $6.8^{\mathrm{d}}$ & $410^{\mathrm{e}}$ & $59^{c}$ \\
\hline & $\omega$-Gli-A1h & $34.7^{b}$ & 13.2 & 94.8 & $34.0^{\mathrm{c}}$ & $4.8^{\mathrm{a}}$ & $8^{d}$ & $430^{\mathrm{e}}$ & $59^{c}$ \\
\hline & $\omega$-Gli-B1b & $38.7^{\mathrm{a}}$ & 12.8 & 94.2 & $35.5^{\mathrm{c}}$ & $5.3^{\mathrm{a}}$ & $9.5^{c}$ & $470^{\mathrm{e}}$ & $59^{\mathrm{c}}$ \\
\hline & $\gamma$-Gli-ma & $39.1^{\mathrm{a}}$ & 12.9 & 92.6 & $33.0^{\mathrm{d}}$ & $4.5^{\mathrm{a}}$ & $7.5^{d}$ & $510^{d}$ & $59^{\mathrm{c}}$ \\
\hline & $\gamma$-Gli-mb & $38.5^{\mathrm{a}}$ & 13.1 & 88.7 & $32.0^{d}$ & $4.5^{\mathrm{a}}$ & $7.8^{d}$ & $450^{\mathrm{e}}$ & $59^{c}$ \\
\hline & $\gamma$-Gli-mc & $37.9^{a}$ & 12.9 & 90.2 & $34.0^{c}$ & $4.4^{\mathrm{a}}$ & $7.5^{d}$ & $420^{\mathrm{e}}$ & $59^{\mathrm{c}}$ \\
\hline & $\gamma$-Gli-md & $35.7^{b}$ & 12.4 & 90.5 & $34.8^{\mathrm{c}}$ & $4.0^{b}$ & $7.3^{d}$ & $470^{\mathrm{e}}$ & $59^{c}$ \\
\hline & $\gamma$-Gli-me & $36.3^{b}$ & 12.6 & 92.8 & $34.5^{c}$ & $5.3^{\mathrm{a}}$ & $10.5^{\mathrm{c}}$ & $510^{d}$ & $59^{c}$ \\
\hline \multirow[t]{4}{*}{ Albumin } & Alb-mb & $36.1^{b}$ & 12.5 & 94.2 & $37.0^{b}$ & $4.0^{\mathrm{b}}$ & $10.5^{\mathrm{c}}$ & $550^{\mathrm{c}}$ & $60^{c}$ \\
\hline & Alb-mc & $33.5^{b}$ & 12.6 & 92.5 & $35.0^{\mathrm{c}}$ & $3.5^{b}$ & $9.6^{c}$ & $530^{c}$ & $60^{c}$ \\
\hline & Alb-mf & $35.9^{b}$ & 12.4 & 94.7 & $35.0^{\mathrm{c}}$ & $4.0^{\mathrm{b}}$ & $6.5^{\mathrm{d}}$ & $555^{\mathrm{c}}$ & $60^{c}$ \\
\hline & Alb-mg & $36.3^{b}$ & 12.1 & 95.3 & $34.0^{c}$ & $4.0^{\mathrm{b}}$ & $10.3^{c}$ & $555^{\mathrm{c}}$ & $60^{c}$ \\
\hline
\end{tabular}

Differences in mean values in the same column followed by different letter in superscript are statistically significant

NIL near-isogenic lines; SDS-SV sodium dodecyl sulphate-sedimentation volume

* Means of 4 years data

** Means of 2 years data 
Table 3 Extensigraph and SDS-sedimentation volume scores of $F_{4}$ homozygous seeds segregating for triticin alleles from crosses between HD2329 and triticin NILs

\begin{tabular}{|c|c|c|c|}
\hline \multirow[t]{2}{*}{ Sr. no. } & \multirow[t]{2}{*}{ Genotype } & \multicolumn{2}{|l|}{ Extensiograph } \\
\hline & & Resistance $(\mathrm{cm})$ & SDS-SV (ml) \\
\hline 1. & HD2329 & $0.022^{\mathrm{c}}$ & $35^{\mathrm{b}}$ \\
\hline 2. & NIL Tri-A1a & $0.040^{\mathrm{b}}$ & $44^{\mathrm{a}}$ \\
\hline 3. & NIL Tri-D1a & $0.086^{\mathrm{a}}$ & $46^{\mathrm{a}}$ \\
\hline 4. & Tri-D1a-1 & $0.083^{\mathrm{a}}$ & $45^{\mathrm{a}}$ \\
\hline 5. & Tri-D1a-2 & $0.073^{\mathrm{a}}$ & $44^{\mathrm{a}}$ \\
\hline 6. & Tri-D1a-3 & $0.087^{\mathrm{a}}$ & $45^{\mathrm{a}}$ \\
\hline 7. & Tri-D1a-4 & $0.077^{\mathrm{a}}$ & $45^{\mathrm{a}}$ \\
\hline 8. & Tri-D1a-5 & $0.084^{\mathrm{a}}$ & $45^{\mathrm{a}}$ \\
\hline 9. & Tri-D1a-6 & $0.091^{\mathrm{a}}$ & $44^{\mathrm{a}}$ \\
\hline 10. & Tri-D1a-7 & $0.083^{\mathrm{a}}$ & $44^{\mathrm{a}}$ \\
\hline 11. & Tri-D1a-8 & $0.087^{\mathrm{a}}$ & $44^{\mathrm{a}}$ \\
\hline 12. & Tri-D1a-9 & $0.082^{\mathrm{a}}$ & $44^{\mathrm{a}}$ \\
\hline 13. & Tri-D1b-1 & $0.071^{\mathrm{a}}$ & $38^{\mathrm{b}}$ \\
\hline 14. & Tri-D1b-2 & $0.060^{\mathrm{b}}$ & $38^{\mathrm{b}}$ \\
\hline 15. & Tri-D1b-3 & $0.065^{\mathrm{b}}$ & $36^{\mathrm{b}}$ \\
\hline 16. & Tri-D1b-4 & $0.072^{\mathrm{a}}$ & $38^{\mathrm{b}}$ \\
\hline 17. & Tri-D1b-5 & $0.074^{\mathrm{a}}$ & $36^{b}$ \\
\hline 18. & Tri-D1b-6 & $0.063^{\mathrm{b}}$ & $36^{b}$ \\
\hline 19. & Tri-A1a-1 & $0.044^{\mathrm{b}}$ & $45^{\mathrm{a}}$ \\
\hline 20. & Tri-A1a-2 & $0.040^{\mathrm{b}}$ & $44^{\mathrm{a}}$ \\
\hline 21. & Tri-A1a-3 & $0.041^{\mathrm{b}}$ & $44^{\mathrm{a}}$ \\
\hline 22. & Tri-A1a-4 & $0.038^{\mathrm{b}}$ & $45^{\mathrm{a}}$ \\
\hline 23. & Tri-A1a-5 & $0.038^{\mathrm{b}}$ & $44^{\mathrm{a}}$ \\
\hline 24. & Tri-A1a-6 & $0.037^{\mathrm{b}}$ & $44^{\mathrm{a}}$ \\
\hline 25. & Tri-A1a-7 & $0.039^{\mathrm{b}}$ & $44^{\mathrm{a}}$ \\
\hline 26. & Tri-A1a-8 & $0.046^{\mathrm{b}}$ & $45^{a}$ \\
\hline 27. & Tri-A1b-1 & $0.023^{\mathrm{c}}$ & $35^{\mathrm{b}}$ \\
\hline 28. & Tri-A1b-2 & $0.019^{c}$ & $34^{\mathrm{b}}$ \\
\hline 29. & Tri-A1b-3 & $0.023^{\mathrm{c}}$ & $35^{\mathrm{b}}$ \\
\hline 30. & Tri-A1b-4 & $0.019^{\mathrm{c}}$ & $35^{\mathrm{b}}$ \\
\hline 31. & Tri-A1b-5 & $0.026^{\mathrm{c}}$ & $35^{\mathrm{b}}$ \\
\hline & $\mathrm{SD}( \pm)$ & 0.025 & 3 \\
\hline & SEM $( \pm)$ & 0.0047 & 0.676 \\
\hline
\end{tabular}

Values in the same column followed by different superscript letter are significantly different at cutoff $P$ value of $5 \%$

also similar behaviour of HMW-GS alleles was observed. Among the alleles present in the different loci of HMWGS, 1 and $2^{*}$ at Glu-Al locus, $17+18$ and $7+8$ at Glu$B 1,5+10$ at $G l u-D 1, d$ at Glu-A3, and $b$ at $G l u-B 3$ have all been described as having a positive effect on breadmaking quality [4]. Here also we have observed similar behaviour where all the HMW-GS alleles are behaving positively except $G l u-A 1 c$ which is a null allele and behaving negatively. Uthayakumaran et al. also observed that the presence of Glu-Dld (subunits $5+10$ ) makes a

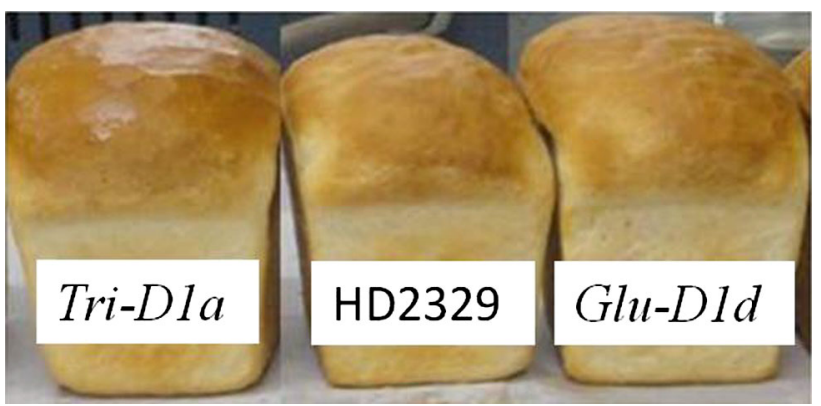

Fig. 7 Comparison of representative bread loaves baked from flour of, $a$ NIL Tri-D1a, $b$ Recipient variety HD2329, $c$ NIL Glu-D1d (subunit $5+10$ ), showing comparable effects of triticin and HMW subunits

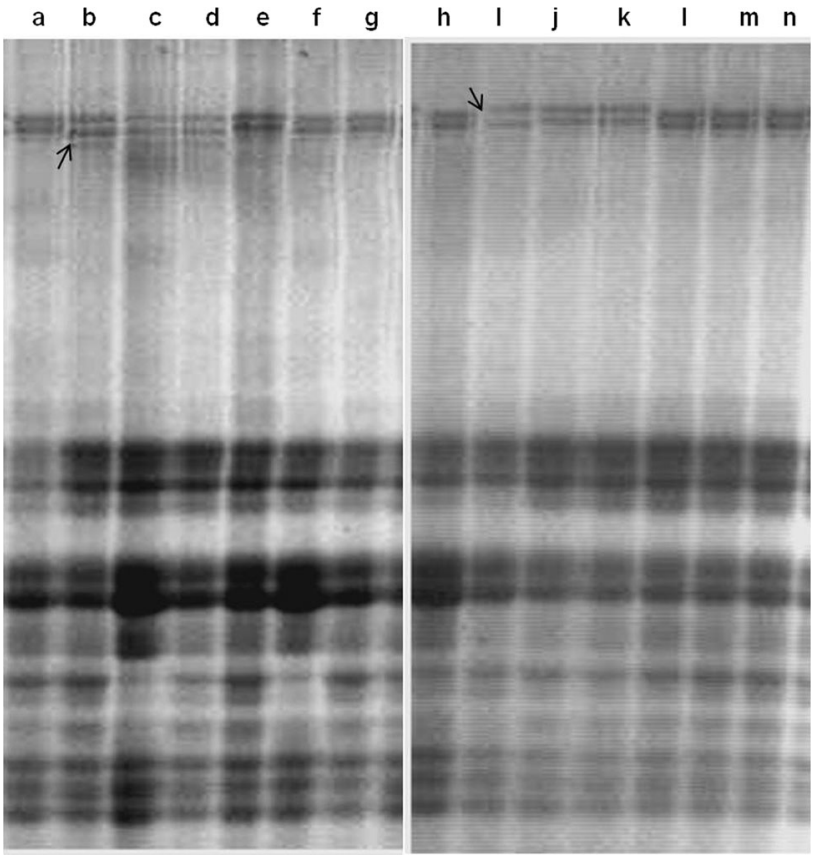

Fig. 8 SDS-PAGE patterns of homozygous $F_{3}$ lines selected from segregating bi-parental populations obtained by crossing recipient parent HD2329 with triticin NIL Tri-A1a $(b-g)$ and Tri-D1a $(i-n) . a$, $h$ Recipient parent HD2329, $b-d$ lines with triticin allele Tri-A1a (marked with arrow), $e-g$ lines with triticin allele Tri-A1b (identical to HD2329), $i-k$ lines with triticin allele Tri-D1a (marked with arrow), $l-n$ lines with triticin allele Tri-D1b (identical to HD2329)

significantly larger contribution to dough properties than those encoded by Glu-Bl $(17+18)$, while subunit 1 encoded by Glu-Al made the smallest contribution to functionality [39]. Sontag-Strohm et al. found that progeny carrying allele Glu-Alb (subunit 2*) had significantly greater SDS sedimentation-volumes than the null allele Glu-Alc, and that adding a HMW glutenin subunit affected extensiograph dough strength more than adding a LMW glutenin subunit, although both increased the SDSsedimentation volumes [37]. 
LMW glutenin subunits have also been shown to significantly impact the dough strength in bread wheat [6]. In our study, seven NILs with different LMW glutenin subunits were analysed, and it was found that in comparison to HD2329 allele $(G l u-A 3 b)$ other Glu-A3 alleles showed negative or no significant effect on bread-making quality, except allele $G l u-A 3 d$ which had a significant positive effect. Earlier Gupta et al. also found association of gliadins and linked $G l u-A 3 b$ allele with dough resistance and extensibility in bread wheat [6]. Glu-A3a was found to be superior to Glu$A 3 e$ and $G l u-A 3 b$ was superior to $G l u-A 3 c[5,7,8,17]$. In our study, Glu-A3a, Glu-A3c and Glu-A3e negatively affected the quality, whereas Glu-A3d, Glu-B3ks and Glu-D5a showed positive effect on the dough properties. Effect of gliadins in determining bread-making quality was variable. Some alleles of $\gamma$-gliadins were found to have no significant effect on dough properties, while others were found to be negatively correlated with loaf volume, but none of the Gliadin NILs showed positive effect. Studies on the effect of albumin on wheat quality are limited. Here, we found that four NILs with different alleles of albumin have no significant effect on wheat quality. While effect of glutenin subunits have been reported in several earlier studied, this is the first report on effect of triticin on bread- and chapatimaking quality of wheat which can be utilized for the improvement of wheat end-use quality.

\section{Conclusions and Prospects}

Significant differences in dough rheological properties and end-use quality for bread and chapati making were observed among NILs with different seed protein alleles in a common genetic background of wheat variety HD2329. While results with the major classes of seed storage proteins namely glutenin and gliadin were confirmatory in nature, a positive effect of wheat storage globulin triticin on the bread- and chapati-making qualities of wheat is demonstrated here for the first time. Also, it is for the first time that the effect of allelic differences at five different classes of seed protein loci have has been analysed in common genetic background. In future, we can study interaction effects of these genes in the common background of HD2329 by making intercrosses and selecting different assortments of alleles. We also need to develop more NILs for a comprehensive coverage of seed storage protein alleles. The information generated here will be very useful in developing high yielding wheat varieties with improved end-use quality.

Acknowledgments We are grateful to the Department of Biotechnology, Government of India Wheat Quality Network Project and ICAR Network Project on Transgenics in Crops (NPTC) for providing funding support.
Open Access This article is distributed under the terms of the Creative Commons Attribution License which permits any use, distribution, and reproduction in any medium, provided the original author(s) and the source are credited.

\section{References}

1. AACC approved methods of the AACC (10th ed.) American Association of Cereal Chemists St Paul, MN (2003)

2. Axford DC, McDermott D, Redman D (1978) Small scale tests of breadmaking quality. Milling Feed Fertil 66:18-20

3. Bechtel DB, Wilson JD, Shewry PR (1991) Immunocytochemical localization of the wheat storage protein triticin in developing endosperm tissue. Cereal Chem 68(6):573-577

4. Branlard G, Dardevet M (1985) Diversity of grain protein and bread wheat quality II. Correlation between high molecular weight subunits of glutenin and flour characteristics. J Cereal Sci 3:345-354

5. Gupta RB, MacRitchie F (1994) Allelic variation at glutenin subunit and gliadin loci, Glu-1, Glu-3 and Gli-1 of common wheats. II. Biochemical basis of the allelic effects on dough properties. J Cereal Sci 19:19-29

6. Gupta RB, Shepherd KW (1987) Genetic control of LMW glutenin subunits in bread wheat and association with physical dough properties. In: Lasztity R, Bakes F (Eds) Proceedings of the 3rd international workshop on gluten proteins, World Scientific Publishers, Singapore, pp 13-19

7. Gupta RB, Shepherd KW (1988) Low-molecular-weight glutenin subunits in wheat: their variation, inheritance, and association with physical dough properties. In: Miller TE, Koebner RMD (Eds), Proceedings of the 7th international wheat genetics symposium, Cambridge, pp 943-949

8. Gupta RB, Singh NK, Shepherd KW (1989) The cumulative effect of allelic variation in LMW and HMW glutenin subunits on dough properties in the progeny of 2 bread wheats. Theor Appl Genet 77:57-64

9. Gupta RB, Khan K, MacRitchie F (1993) Biochemical basis of flour properties in bread wheats. I. Effects of variation in the quantity and size distribution of polymeric protein. J Cereal Sci 18:23-44

10. Haridas Rao P, Leelavathi K, Shurpalekar SR (1987) Objective measurement of the consistency of chapati dough using research water absorption meter. J Texture Stud 17:401

11. Lawrence GJ, Macritchie F, Wrigley CW (1988) Dough and baking quality of wheat lines deficient in glutenin subunits controlled by the Glu-Al, Glu-B1 and Glu-D1 loci. J Cereal Sci 7:109-112

12. Leisle D, Kosmolak FG, Kovacs M (1981) Association of glume color with gluten strength and gliadin proteins in durum wheat. Can J Plant Sci 61:149-151

13. Liang D, Tang JW, Pena RJ, Singh R, He XY, Shen XY, Yao DN, Xia XC, He ZH (2010) Characterization of CIMMYT bread wheats for high- and low-molecular weight glutenin subunits and other quality-related genes with SDS-PAGE, RP-HPLC and molecular markers. Euphytica 172:235-250

14. MacRitchie F (1985) Studies of the methodology for fractionation and reconstitution of wheat flours. J Cereal Sci 3:221-230

15. MacRitchie F (1987) Evaluation of contributions from wheat protein fractions to dough mixing and breadmaking. J Cereal Sci 6:259-268

16. Osborne T B (1907) The protein of the wheat kernel. Publication No. 84. Carnegie Institute, Washington, DC 
17. Payne PI (1987) Genetics of wheat storage proteins and the effect of allelic variation on bread-making quality. Annu Rev Plant Physiol 38:141-153

18. Payne PI, Lawerence G (1983) Catalogue of alleles foe the complex gene loci, Glu-A1, Glu-B1 and Glu-D1 which code for high molecular weight subunits of glutenins in hexaploid wheat. Cereal Res Commun 11:29-35

19. Payne PI, Corfield KG, Blackman JA (1979) Identification of a high-molecular-weight subunit of glutenin whose presence correlates with bread-making quality in wheats of related pedigree. Theor Appl Genet 55:153-159

20. Payne PI, Nightingale MA, Krattiger AF, Holt LM (1987) The relationship between HMW glutenin subunit composition and the bread making quality in British grown wheat varieties. J Food Sci Agric 40:51-65

21. Pence JW, Nimmo CC (1964) New knowledge of wheat proteins. Bak Dig 38(1):38-42

22. Rathore M (2002) Production of near isogenic lines with different wheat seed protein alleles. Indian Agriculture Research Institute

23. Rathore M, Mishra DP, Singh NK (2003) Screening of wheat varieties for use as donors for production of near isogenic lines with different seed protein alleles. Indian Soc Genet Plant Breed 63:206-208

24. Sapirstein HD, Fu BX (1998) Intercultivar variation in the quantity of monomeric proteins, soluble and insoluble glutenin, and residue protein in wheat flour and relationships to breadmaking quality. Cereal Chem 75:500-507

25. Shailja K, Rathore M, Puri N, Yadav D, Singh NK (2002) PCR amplification of hypervariable region of wheat triticin gene. J Cereal Sci 35:129-134

26. Shewry PR, Tatham AS (1990) The prolamin storage proteins of cereal seeds: structure and evolution. J Biochem 267:1-12

27. Singh H, MacRitchie F (2001) Application of polymer science to properties of gluten. J Cereal Sci 33:231-243

28. Singh NK, Shepherd KW (1985) The structure and genetic control of a new class of disulphide-linked proteins in wheat endosperm. Theor Appl Genet 71:79-92

29. Singh NK, Shepherd KW (1987) Solubility behaviour, synthesis, degradation and subcellular location of new class of disulfidelinked proteins in wheat endosperm. Aust J Plant Physiol 114:245-252

30. Singh NK, Shepherd KW (1988) Linkage mapping of genes controlling endosperm storage proteins in wheat. Theor Appl Genet 75:642-650
31. Singh NK, Shepherd KW (1988) Linkage mapping of the genes controlling endosperm storage proteins in wheat. I. Genes on the short arms of group-1 chromosomes. Theor Appl Genet 75:628-641

32. Singh NK, Shepherd KW, Langridge P, Gruen LC, Skerritt JH, Wrigley CW (1988) Identification of legumin like protein in wheat. Plant Mol Biol 11:633-639

33. Singh NK, Donovan GR, Batey IL, MacRitchie F (1990) Use of sonication and size-exclusion high performance liquid chromatography in the study of wheat flour proteins. I. Dissolution of total proteins in the absence of reducing agents. Cereal Chem 67:150-161

34. Singh NK, Donovan GR, MacRitchie F (1990) Use of sonication and high performance liquid chromatography in the study of wheat flour proteins. II Relative quantity of glutenin as measure of bread making quality. Cereal Chem 67:161-170

35. Singh NK, Shepherd KW, Cornish GB (1991) A simplified SDS PAGE procedure for separating LMW subunits of glutenin. J Cereal Sci 14:203-208

36. Singh NK, Donovan GR, Carpenter HC, Skerritt JH, Langridge P (1993) Isolation and characterization of wheat triticin cDNA revealing a unique lysine rich repetitive domain. Plant Mol Biol 22:227-237

37. Sontag-Strohm T, Payne PI, Salovaara H (1996) Effect of allelic variation of glutenin subunits and gliadins on baking quality in the progeny of two biotypes of bread wheat cv. Ulla. J Cereal Sci 24:115-124

38. Sreeramalu G, Singh NK (1995) Destaining of coomassie brilliant blue R-250 stained polyacrylamide gels with sodium chloride solutions. Electrophoresis 16:362-365

39. Uthayakumaran S, Tomoskozi S, Tatham AS, Savage AWJ, Gianibelli MC, Stoddard FL, Bekes F (2001) Effects of gliadin fractions on functional properties of wheat dough depending on molecular size and hydrophobicity. Cereal Chem 78:138-141

40. Woychik JH, Boundy JA, Dimler RJ (1961) Starch gel electrophoresis of wheat gluten proteins with concentrated urea. Arch Biochem Biophys 94:477-482

41. Wrigley CW, Shepherd KW (1973) Electrofocusing of grain proteins from wheat genotypes. Ann N Y Acad Sci 209:154-162

42. http://icar.org.in/en/node/6512

43. Zaidel ADN, Chin NL, Yusof YA (2010) A review on rheological properties and measurements of dough and gluten. J Appl Sci 10(20):2478-2490 